\title{
ИСПОЛЬЗОВАНИЕ НЕТРАДИЦИОННЫХ КОРМОВЫХ ДОБАВОК В ВЫРАЩИВАНИИ МОЛОДНЯКА СВИНЕЙ В УСЛОВИЯХ ЯКУТИИ
}

\author{
N.M. Chernogradskaya, M.F. Grigoriev, \\ A.I. Grigorieva
}

\section{USING NONCONVENTIONAL FEED ADDITIVES IN GROWING YOUNG GROWTH OF PIGS IN THE CONDITIONS OF YAKUTIA}

Черноградская Н.М. - канд. С.-х. наук, доц. каф. общей зоотехнии Якутской государственной сельскохозяйственной академии, г. Якутск.

E-mail: grig_mf@mail.ru

Григорьев М.Ф. - канд. с.-х. наук, ст. преп. кафр. общей зоотехнии Якутской государственной сельскохозяйственной академии, г. Якутск.

E-mail: grig_mf@mail.ru

Григорьева А.И. - ст. преп. каф. высшей математики Северо-Восточного федерального университета им. М.К. Аммосова, г. Якутск, магистрант кафр. общей зоотехнии Якутской государственной сельскохозяйственной академии, г. Якутск.

E-mail: grig_mf@mail.ru

Целью научно-хозяйственного опыта являлось изучение роста и развития молодняка свиней крупной белой породы при включении в рацион цеолита хонгурин в условиях Якутии. Задачи: изучение влияния цеолита хонгурина на показатели живой массы подопытных животных; установление влияния цеолита хонгурина на среднесуточный прирост подопытного молодняка свиней крупной белой породы. Научный опыт по выращиванию молодняка свиней крупной белой породы проведен на базе ООО «Хатасский свинокомплекс». Продолжительность опыта 120 дней. В ходе исследований были использованы общепринятые в зоотехнии методики. Согласно программе исследований были сформированы 3 группы подопытного молодняка по 15 голов в каждой. Группы были сфрормированы по принципу аналогов, где учитывались такие показатели, как возраст, живая масса и клинические показате-
Chernogradskaya N.M. - Cand. Agr. Sci., Assoc. Prof., Chair of General Zootechnics, Yakut State Agricultural Academy, Yakutsk.

E-mail: grig_mf@mail.ru

Grigoriev M.F. - Cand. Agr. Sci., Senior Lecturer, Chair of General Zootechnics, Yakut State Agricultural Academy, Yakutsk.

E-mail: grig_mf@mail.ru

Grigorieva A.I. - Senior Lecturer, Chair of Higher Mathematics, North-Eastern Federal University named after M. K. Ammosov, Yakutsk, Magistrate Student, Chair of General Zootechnics, Yakut State Agricultural Academy, Yakutsk.

E-mail: grig_mf@mail.ru

ли. В ходе исследований было установлено, что включение хонгурина в норме 0,15 и 0,18 грамм на килограмм живой массы в рационы выращиваемого молодняка в опытных группах значительно увеличило прирост живой массы животных. По динамике живой массы контрольная группа уступила I и II опытным группам в конце опыта соответственно на 3,08 и 6,42\%. Включение хонгурина в основной рацион опытных групп молодняка способствовало увеличению среднесуточного прироста. По периодам выращивания I и II опытные группы превосходили сверстников с контрольной: в 60-90 дней на 5,88 и 11,66 \%; в 90 105 дней - на 5,10 и 10,58 \%; в 105-120 дней на 17,17 и 25,46 \%; в 120-150 дней - на 11,36 и 14,91 \%; в 150-180 дней - на 7,08 и 7,09 \% соответственно. 
Ключевые слова: рацион, минеральные вещества, кормление, свиноводство, молодняк, корма, продуктивность, Якутия.

The purpose of scientific and economic experiment was studying the growth and development of young growth of pigs of large white breed at adding into their feeding of zeolite hongurin in the conditions of Yakutia. The tasks were studying the influence of zeolite hongurin on the indicators of live mass of experimental animals; the establishment of the influence of zeolite hongurin on an average daily gain of experimental large white breed pigs' young growth. Scientific experiment on growing of large white breed pigs' young growth was made on the basis of JSC 'Hatassky Pig Factory Farm'. The experiment lasted 120 days. During the researches the standard techniques in zootechnics were used. According to the program of the researches 3 groups of experimental young growth up to 15 heads in each were created. The groups were created by the principle of analogs where such indicators as age, live weight and clinical indicators were considered. During the researches it was established that inclusion of hongurin in norm of 0.15 and 0.18 grams in feeding grown-up young growth in experimental groups considerably increased live mass gain of animals by 1 kilogram of live weight. On the dynamics of live weight the control group conceded to I and II experimental groups at the end of the experiment respectively for 3.08 and $6.42 \%$. The inclusion of hongurin in the main diet of experimental groups of young growth promoted the increase in average daily gain. I and II experimental groups surpassed the contemporaries in growing periods with control: in 60-90 days for 5.88 and $11.66 \%$; in 90-105 days - for 5.10 and $10.58 \%$; in 105-120 days for 17.17 and $25.46 \%$; in 120-150 days - for 11.36 and $14.91 \%$; in 150-180 days for 7.08 and $7.09 \%$, respectively.

Keywords: feeding, mineral substances, feeding, pig-breeding, young growth, feeds, efficiency, Yakutia.
Введение. Известно, что интенсификация отрасли животноводства, реализация потенциала животных и, как следствие, высокая рентабельность производства аграрной продукции зависят от организации наиболее полноценного и сбалансированного кормления [1, 2].

При полноценном кормлении животных должно учитываться достаточное обеспечение потребностей животного в необходимых минеральных элементах питания в соответствии с научно обоснованными рекомендациями $[3,4]$.

Необходимо отметить, что при хроническом десиците минеральных веществ в рационах у животных проявляются различные незаразные заболевания, такие как рахит, перегулы и бесплодие, рождение слабого приплода, а также понижение биологической ценности получаемой аграрной продукции $[5,6]$.

В практике кормления в качестве альтернативного решения вопроса обеспечения минерального питания животных применяют различные минеральные ресурсы, среди которых эффективно зарекомендовали себя различные цеолиты, сапропели и минеральные соли $[7,8]$.

В условиях Якутии имеется крупное месторождение цеолитов в Сунтарском районе (месторождение Хонгуруу) [9]. Это послужило основанием для проведения исследований по возможности вовлечения данного ресурса в кормление свиней в условиях Якутии.

Цель работы. Исследование использования нетрадиционных кормовых добавок в выращивании молодняка свиней крупной белой породы в условиях Якутии.

Задачи исследований: изучить влияние цеолита хонгурина на показатели живой массы подопытных поросят; установить влияние цеолита хонгурина на среднесуточный прирост молодняка свиней крупной белой породы.

Объекты и методы исследований. Научнохозяйственный опыт проведен на базе $О 00$ «Хатасский свинокомплекс». Для проведения исследований сформировано 3 группы подопытного молодняка крупной белой породы свиней (рис.) согласно схеме (табл. 1). 


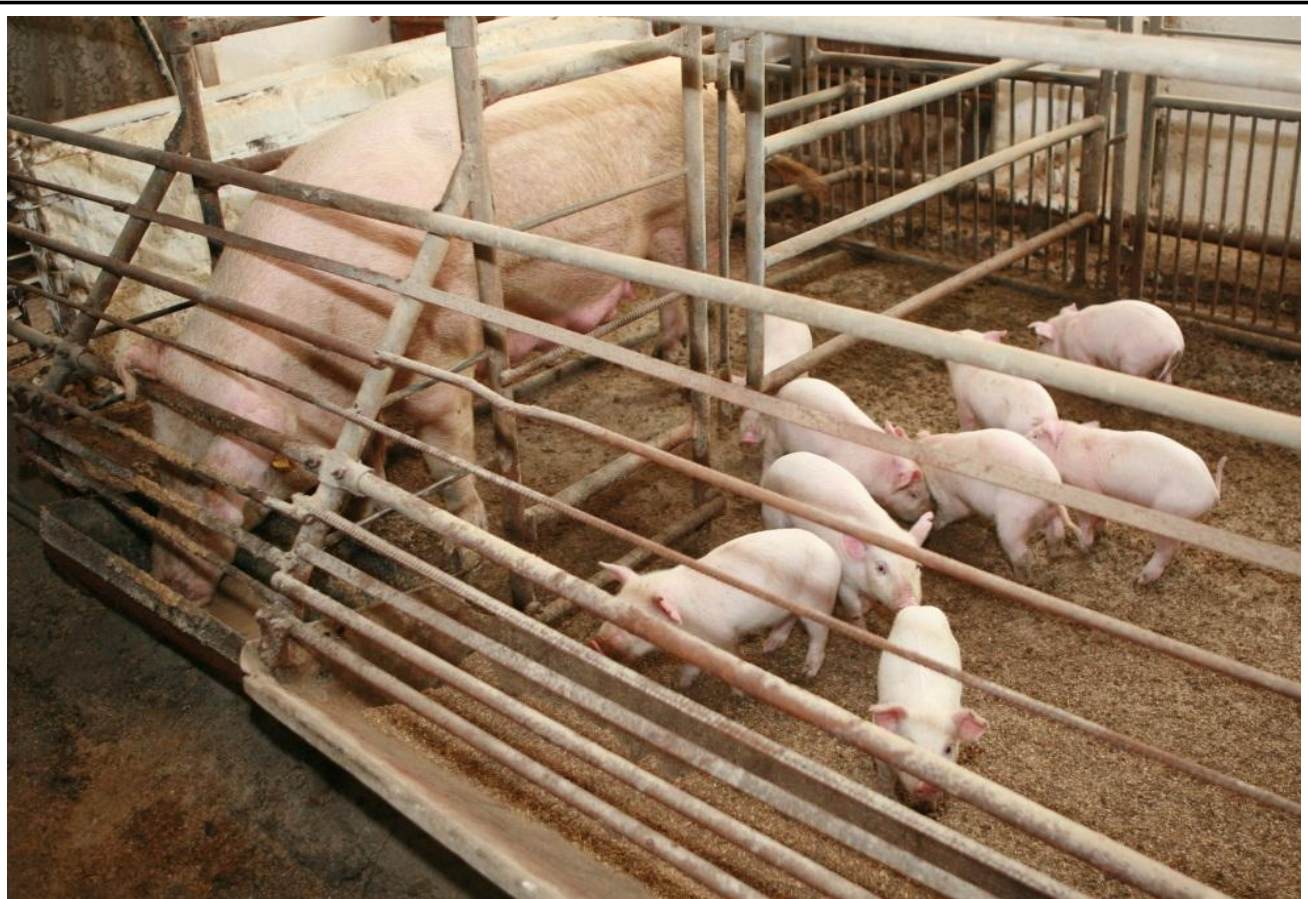

Молодняк свиней крупной белой породы

Схема проведения научно-хозяйственного опыта $(n=15)$

\begin{tabular}{|c|c|}
\hline Группа & Условия научного опыта \\
\hline Контрольная & ОР \\
\hline І опытная & OР + X 0,15 г/Кг ж.М. + К 5 г \\
\hline І опытная & ОР + X 0,18 г/Кг ж.М. + К 6 г \\
\hline
\end{tabular}

Примечание: ОР - основной рацион, $\mathrm{X}$ - цеолит хонгурин, К - кемпендяйская соль.

Группы сформированы по принципу аналогов, где было учтены такие показатели, как возраст, живая масса и физиологическое состояние животных. Условия проведения опытов для всех групп подопытных животных были одинаковыми кроме кормовых добавок в опытных группах.
Рационы свиней соответствуют детализированным нормам кормления [4]. В таблице 2 представлены основные рационы молодняка свиней крупной белой породы по периодам выращивания и откорма (среднесуточный прирост 450550 г) на голову в сутки.

Рацион выращиваемого молодняка крупной белой породы, на голову в сутки

\begin{tabular}{|c|c|c|c|c|c|c|c|c|c|c|c|}
\hline \multirow{2}{*}{ Показатель } & \multirow{2}{*}{\begin{tabular}{|c|} 
Ед. \\
измерения
\end{tabular}} & \multicolumn{10}{|c|}{ Живая масса, кг } \\
\hline & & $15-20$ & $20-30$ & $30-40$ & 40 & 50 & 60 & 70 & 80 & 90 & 100 \\
\hline 1 & 2 & 3 & 4 & 5 & 6 & 7 & 8 & 9 & 10 & 11 & 12 \\
\hline Комбикорм & Кг & 0,8 & 1,0 & 1,3 & 1,2 & 1,4 & 1,5 & 2,8 & 3,0 & 3,4 & 3,7 \\
\hline Молоко цельное сухое & Кг & 0,15 & 0,2 & 0,2 & 0,3 & 0,3 & 0,5 & - & - & - & - \\
\hline Гидропонная зелень & КГ & 0,08 & 0,08 & 0,1 & 0,1 & 0,1 & 0,2 & 0,3 & 0,3 & - & - \\
\hline Рыбные отходы & Кг & 0,1 & 0,1 & 0,1 & 0,2 & 0,2 & - & - & - & - & - \\
\hline
\end{tabular}


Окончание табл. 2

\begin{tabular}{|l|c|c|c|c|c|c|c|c|c|c|c|}
\hline \multicolumn{1}{|c|}{1} & 2 & 3 & 4 & 5 & 6 & 7 & 8 & 9 & 10 & 11 & 12 \\
\hline Мел & г & 3,0 & 5,0 & 6,0 & 10 & 12 & 15 & 16 & 18 & - & - \\
\hline Кормовые единицы & к.ед. & 1,2 & 1,5 & 1,8 & 2,0 & 2,2 & 2,5 & 2,9 & 3,2 & 3,4 & 3,7 \\
\hline Обменная энергия & МДж & 13,7 & 16,2 & 19,7 & 20,8 & 22,3 & 25,4 & 27,3 & 32,1 & 32,0 & 33,1 \\
\hline Сухое вещество & кг & 0,9 & 1,12 & 1,41 & 1,68 & 1,83 & 1,99 & 2,07 & 2,34 & 2,5 & 3,0 \\
\hline Сырой протеин & г & 184 & 225 & 263 & 253 & 271 & 312 & 318 & 348 & 397 & 419 \\
\hline Переваримый протеин & г & 167 & 175 & 211 & 176 & 198 & 222 & 231 & 262 & 277 & 316 \\
\hline Лизин & г & 8,5 & 9,8 & 11,6 & 11 & 12 & 14 & 16,2 & 16,8 & 22,0 & 24,0 \\
\hline Метионин и цистин & г & 4,6 & 5,3 & 6,9 & 7,0 & 8 & 9 & 9,6 & 10,0 & 12 & 13 \\
\hline Сырая клетчатка & $г$ & 32 & 57 & 66 & 108 & 116 & 118 & 162 & 179 & 196 & 211 \\
\hline Кальций & г & 7,8 & 10 & 12 & 12 & 14 & 16 & 18 & 19 & 22 & 24 \\
\hline Фосфрор & г & 6,6 & 8,5 & 9,7 & 10 & 12 & 14 & 16 & 17 & 18 & 19 \\
\hline
\end{tabular}

Минеральный состав цеолита хонгурина месторождения Хонгуруу Сунтарского района Республики Саха (Якутия) представлен следующим составом, \%: SiO - 65,19; TiO - 0,20; AlO - 11,70; $\mathrm{Fe}_{2} \mathrm{O}_{3}-1,05 ; \mathrm{FeO}-0,43 ; \mathrm{MgO}-0,73 ; \mathrm{NaO}-$ 3,03; KO - 1,23; $\mathrm{MnO}-0,005$; $\mathrm{CO}-0,265$; $\mathrm{CaO}$ 2,25; $\mathrm{PO}-0,032 ; \mathrm{HO}-7,66$; V - 0,0019; $\mathrm{Cu}-$ 0,0065; Mo-0,002; Co-0,0001; Be-0,00003; As $-0,00001 ; \mathrm{Fe}-0,00001 ; \mathrm{Hg}-0,00001 ; \mathrm{Sb}-$ $0,00001, \mathrm{Zn}-0,00001[9]$.
Нормы включения цеолита в рацион опытных групп установлены в соответствии с биологическими потребностями животных $[4,5]$.

Данные опыта обработаны в соответствии с методикой [10].

Результаты исследований и их обсуждение. Результаты исследований влияния местных кормовых добавок на рост и развитие поросят крупной белой породы представлены в таблицах 3 и 4.

Изменение живого веса поросят крупной белой породы (M士m), кг

Таблица 3

\begin{tabular}{|c|c|c|c|}
\hline \multirow{2}{*}{ Возраст, дней } & \multicolumn{3}{|c|}{ Группа } \\
\cline { 2 - 4 } & Контрольная & І опытная & I опытная \\
\hline 60 & $16,20 \pm 0,38$ & $16,20 \pm 0,26$ & $16,13 \pm 0,27$ \\
\hline 90 & $25,80 \pm 0,35$ & $26,40 \pm 0,24$ & $27,00 \pm 0,52$ \\
\hline 105 & $32,00 \pm 0,32$ & $32,93 \pm 0,37$ & $33,93 \pm 0,79^{*}$ \\
\hline 120 & $37,47 \pm 0,35$ & $39,53 \pm 0,40^{* * *}$ & $41,27 \pm 0,92^{* * *}$ \\
\hline 150 & $53,07 \pm 0,36$ & $54,13 \pm 0,66$ & $56,60 \pm 1,13^{* *}$ \\
\hline 180 & $67,07 \pm 0,82$ & $69,20 \pm 1,06$ & $71,67 \pm 1,31^{\text {** }}$ \\
\hline
\end{tabular}

Примечание. Здесь и далее: * $P>0.95$ ** $P>0.99$ *** $P>0.999$.

Установлено что включение местных нетрадиционных кормовых добавок в рационы молодняка свиней в опытных группах свиней значительно увеличило рост и развитие животных. Так, контрольная группа поросят в разные возрастные периоды выращивания уступила по показателям живой массы I и ІІ опытным группам животным в 90 дней на 2,27 и 4,44 \%; при достижении возраста 105 дней - 2,82 и 5,69 \%; в 120 дней - 5,21 и 9,21\%; в 150 дней - 1,96 и 6,24\%; при достижении 180 дней - на 3,08 и $6,42 \%$ соответственно. 
Среднесуточный привес подопытных поросят крупной белой породы (n=15), г

\begin{tabular}{|c|c|c|c|}
\hline \multirow{2}{*}{ Возраст, дней } & \multicolumn{3}{|c|}{ Группа } \\
\cline { 2 - 4 } & Контрольная & І опытная & I опытная \\
\hline $60-90$ & $320,00 \pm 10,69$ & $340,00 \pm 5,82$ & $362,22 \pm 10,22^{* *}$ \\
\hline $90-105$ & $413,33 \pm 9,65$ & $435,56 \pm 11,02$ & $462,22 \pm 22,97$ \\
\hline $105-120$ & $364,44 \pm 8,89$ & $440,00 \pm 18,17^{* * *}$ & $488,89 \pm 24,05^{\star * *}$ \\
\hline $120-150$ & $520,00 \pm 7,13$ & $586,67 \pm 9,65^{*}$ & $611,11 \pm 12,03$ \\
\hline $150-180$ & $466,67 \pm 6,97$ & $502,22 \pm 13,07^{*}$ & $502,22 \pm 7,84^{* *}$ \\
\hline
\end{tabular}

Хонгурин способствовал значительному увеличению среднесуточного прироста молодняка опытных групп. По периодам выращивания контрольная группа уступила опытным группам по периодам роста: в 60-90 дней на 5,88 и 11,66 \%; в 90-105 дней - 5,10 и 10,58 \%; в 105-120 дней - 17,17 и 25,46\%; в 120-150 дней - 11,36 и 14,91\%; в 150-180 дней - на 7,08 и 7,09 \% соответственно.

Выводы. Таким образом, использование цеолита хонгурина в качестве кормовой добавки в составе рационов выращиваемого молодняка свиней в опытных группах значительно увеличило рост и развитие животных на 3,08 и 6,42 \%. По результатам исследования предлагаем включать в суточные рационы выращиваемого молодняка свиней нетрадиционные кормовые добавки по норме 0,18 г/кг живой массы цеолита хонгурина и 6 г кемпендяйской соли.

\section{Литература}

1. Колесняк И.А., Колесняк А.А. Рациональная кормовая база - основа роста производства продукции животноводства // Вестник КрасГАУ. - 2014. - № 9 (96). - С. 42-47.

2. Морозова Л.А. Минерально-витаминные премиксы в кормлении высокопродуктивных коров // Вестник КрасГАУ. - 2007. № 2. - С. 192-196.

3. Оптимизация энергопротеинового отношения в рационах нетелей енисейского типа красно-пестрой породы в сухостойный период и коров-первотелок в фазах раздоя и середины лактации / А.И. Голубков, С.В. Шадрин, А.А. Голубков [и др.] // Вестник КрасГАУ. - 2013. - № 3 (78). - С. 107-116.
4. Калашников А.П. Нормы и рационы кормления сельскохозяйственных животных: справ. пособие / под ред. А.П. Калашникова, В.И. Фисинина, В.В. Щеглова [и др.]. 3-е изд., перераб. и доп. - М.: Россельхозакадемия, 2003. - $456 \mathrm{c}$.

5. Гамидов М.Г., Быстрова Е.Г. Перспективы применения местных минеральных ресурсов в животноводстве Дальнего Востока // Успехи наук о жизни. - 2009. - № 1. C. 153-161.

6. Остякова M.E. Болезни обмена веществ крупного рогатого скота, связанные с неполноценным кормлением // Вестник КрасГАУ. - 2015. - № 12 (111). - С. 195-198.

7. Алтухов И.В., Цугленок Н.В. Применение продуктов высокой биологической активности для повышения продуктивности сельскохозяйственных животных // Вестник КрасГАУ. - 2015. - № 3 (102). - С. 111-114.

8. Черноградская Н.М., Григорьев М.Ф., Григорьева А.И. Цеолит месторождения Хонгуруу в рационе молодняка гусей // Птицеводство. - 2018. - № 3. - С. 18-21.

9. Колодезников К.Е. Цеолитоносные провинции Востока Сибирской платформы. Якутск: Ин-т проблем нести и газа, 2003. $221 \mathrm{c}$.

10. Плохинский Н.А. Руководство по биометрии для зоотехников: учеб. пособие. - М.: Колос, 1969. - 328 с.

\section{Literatura}

1. Kolesnjak I.A., Kolesnjak A.A. Racional'naja kormovaja baza - osnova rosta proizvodstva produkcii zhivotnovodstva // Vestnik KrasGAU. - 2014. - № 9 (96). - S. 42-47. 
2. Morozova L.A. Mineral'no-vitaminnye premiksy v kormlenii vysokoproduktivnyh korov // Vestnik KrasGAU. - 2007. - № 2. - S. 192-196.

3. Optimizacija jenergoproteinovogo otnoshenija $\checkmark$ racionah netelej enisejskogo tipa krasnopestroj porody $v$ suhostojnyj period i korovpervotelok $\mathrm{v}$ fazah razdoja i serediny laktacii / A.I. Golubkov, S.V. Shadrin, A.A. Golubkov [i dr.] // Vestnik KrasGAU. - 2013. - № 3 (78). - S. 107-116.

4. Kalashnikov A.P. Normy i raciony kormlenija sel'skohozjajstvennyh zhivotnyh: sprav. posobie I pod red. A.P. Kalashnikova, V.I. Fisinina, V.V. Shheglova [i dr.]. - 3-e izd., pererab. i dop. - M.: Rossel'hozakademija, 2003. - 456 s.

5. Gamidov M.G., Bystrova E.G. Perspektivy primenenija mestnyh mineral'nyh resursov $v$ zhivotnovodstve Dal'nego Vostoka // Uspehi nauk o zhizni. - 2009. - № 1. - S. 153-161.
6. Ostjakova M.E. Bolezni obmena veshhestv krupnogo rogatogo skota, svjazannye s nepolnocennym kormleniem // Vestnik KrasGAU. - 2015. - № 12 (111). S. 195-198.

7. Altuhov I.V., Cuglenok N.V. Primenenie produktov vysokoj biologicheskoj aktivnosti dlja povyshenija produktivnosti sel'skohozjajstvennyh zhivotnyh // Vestnik KrasGAU. 2015. - № 3 (102). - S. 111-114.

8. Chernogradskaja N.M., Grigor'ev M.F., Grigor'eva A.I. Ceolit mestorozhdenija Honguruu $\mathrm{V}$ racione molodnjaka gusej // Pticevodstvo. 2018. - № 3. - S. 18-21.

9. Kolodeznikov K.E. Ceolitonosnye provincii Vostoka Sibirskoj platformy. - Jakutsk: In-t problem nefti i gaza, 2003. - $221 \mathrm{~s}$.

10. Plohinskij N.A. Rukovodstvo po biometrii dlja zootehnikov: ucheb. posobie. - M.: Kolos, 1969. - $328 \mathrm{~s}$. 